\title{
PERCEPÇÃO DO IMPACTO DA NBR 15575 NA SUSTENTABILIDADE DA EDIFICAÇÃO
}

\author{
João Marcos Bosi Mendonça de Moura \\ Doutorando em Engenharia Ambiental \\ Fundação Universidade Regional de Blumenau, FURB \\ joaomarcosmm@hotmail.com \\ Jéssica Trettin dos Santos \\ Fundação Universidade Regional de Blumenau, FURB \\ jessica.trettin@hotmail.com
}

\section{Ivone Gohr Pinheiro}

Doutora em Physique et Chimie de Lenvironnement - Institut National Polytechnique de Toulouse Professora Titular da Fundação Universidade Regional de Blumenau, FURB ivonegp@furb.br

\begin{abstract}
RESUMO
A construção civil brasileira tem enfatizado tanto a qualidade de processos e produtos como aspectos relacionados à sustentabilidade. Destaca-se a contribuição que a NBR 15575 traz às temáticas, ao versar sobre requisitos e critérios de desempenho de edificações habitacionais. Neste sentido, esta pesquisa analisou a percepção de construtoras e incorporadoras do município de Blumenau-SC, no que tange aos impactos da NBR 15575 na sustentabilidade ambiental das edificações. Entrevistas não estruturadas foram aplicadas aos responsáveis técnicos das empresas, tendo sido possível constatar que apenas $30 \%$ dos entrevistados conhecem a norma. Ademais, um significativo grupo afirmou que ela impacta muito mais no custo do que propriamente na sustentabilidade ambiental da obra. Esta percepção, contudo, não impede a aplicação de medidas voltadas ao uso racional de água e energia, bem como à gestão de resíduos, sendo estas ações consideradas uma obrigatoriedade. Entretanto, a Vida Útil de Projeto ainda é pouco levada em conta. Referente ao Manual de Uso, Operação e Manutenção, os entrevistados percebem que os usuários o utilizam de forma incipiente. Por fim, concluiu-se que as empresas entrevistadas têm uma significativa consciência quanto à sustentabilidade ambiental, porém não a percebem relacionada à ecoeficiência organizacional.
\end{abstract}

Palavras-chave: Desempenho; Durabilidade; Ecoeficiência.

\section{IMPACT OF PERCEPTION OF NBR 15575 IN CONSTRUCTION SUSTAINABILITY}

\begin{abstract}
The Brazilian construction industry has emphasized both the quality of processes and products as relevant aspects related to environmental sustainability. It is important to highlight the contribution that NBR 15575 brings to the subject, approaching requirements and performance criteria for construction of buildings. In this sense, this research analyzed the perception of constructors and incorporators at the city of BlumenauSC, regarding the NBR 15575 impact in the environmental sustainability of buildings. Non-structured interviews were applied to the technical managers of companies and it was possible to verify that only $30 \%$ of respondents know the standard NBR 15575. Moreover, a significant group stated that this norms impact more than the cost of environmental sustainability of the construction. This perception, however, does not hinder the application of measures aimed at rational use of water and energy as well as waste management, those actions being considered as a requirement. However the Useful Life of Project is still not taken into account. Regarding the User's Manual, Operation and Maintenance, respondents perceive that users utilize them in an incipient way. The companies interviewed have showed a relevant awareness of environmental sustainability, but they did not realize the relationship between sustainability and organizational ecoefficiency.
\end{abstract}

Key words: Performance; Durability; Eco-efficiency. 


\section{INTRODUÇÃO}

No Brasil, a construção civil tem tido relativa expansão nas últimas décadas. Tal crescimento tem levado a diversas consequências positivas, principalmente para a economia do país. No entanto, também é necessário considerar a qualidade de processos e produtos e a redução dos impactos ambientais negativos, aspectos cada vez mais cobrados das organizações (Rodríguez, Alegre \& Martínez, 2011).

Neste sentido, questões pertinentes à gestão de resíduos da construção civil, ao conforto térmico, acústico e à durabilidade das edificações ganham espaço e merecido destaque por meio de normas técnicas e instrumentos jurídicos que regulam e padronizam estas atividades, responsáveis por uma significativa parte do consumo mundial de materiais (Isaia \& Ino, 2007).

Por isso, desde a fase de projeto, recomenda-se que o enfoque no desempenho seja incorporado, tendo em vista que este aspecto se relaciona fortemente com a durabilidade e a sustentabilidade ambiental da edificação (Oliveira \& Mitidieri Filho, 2012). O aparecimento de patologias em edifícios habitacionais é um exemplo de que a obsolescência precoce da edificação relaciona-se significativamente com o aumento na demanda de recursos naturais (Boselli \& Dunowicz, 2009). Destaca-se a relação entre dois fatores notadamente importantes na construção civil, o desempenho e a sustentabilidade ambiental.

No que diz respeito ao desempenho, destaca-se a discussão em torno dos requisitos da "NBR 15575 - Edifícios Habitacionais - Desempenho" (ABNT, 2013). Trata-se de uma norma que estabelece requisitos e critério mínimos de desempenho, possíveis de serem mensurados ao longo da vida útil da edificação. Sua primeira versão foi publicada em 2008, tendo passado por revisões em 2010, 2012 e 2013, entrando em vigor em 19 de julho de 2013.

Tal norma apresenta muitos desafios operacionais relacionados à execução de ensaios, monitoramento de parâmetros físicos e adequação de fornecedores de materiais (Kern, Silva \& Kazmierczak, 2014). Todavia, ela também propõe muitos avanços do ponto de vista de sustentabilidade ambiental, pois visa potencializar a gestão de resíduos, a vida útil, o conforto térmico e acústico, o uso racional de água e de energia de empreendimentos habitacionais. Tratam-se todos estes de fatores interdependentes com a sustentabilidade ambiental da edificação. Entretanto, como é percebida essa relação desempenho/sustentabilidade entre os profissionais da construção civil? Quais são as fragilidades e os desafios no que concerne aos aspectos ambientalmente sustentáveis da norma e das práticas correntes do setor?

Para melhor compreender a influência desta norma na sustentabilidade ambiental de um setor tão importante como é a construção civil, acredita-se ser fundamental considerar as práticas, teorias e os processos envolvidos no setor. Isso não significa abordar a problemática de um modo apenas holístico, considerando desde a idealização do projeto até o fim da vida útil da edificação (Motta \& Aguillar, 2009), mas cabe também refletir a respeito de como, na ótica ambiental, as empresas relacionam e sistematizam os processos da construção civil nos seus variados níveis (econômicos, operacionais, sociais, culturais).

\section{SUSTENTABILIDADE NA CONSTRUÇÃO CIVIL}

A sustentabilidade na construção civil refere-se à integração de aspectos ambientais, sociais e econômicos nas estratégias de gestão e nas práticas de negócios. Isto implica num olhar sistêmico para todo o ciclo da construção, iniciando-se com a extração de recursos naturais (matéria-prima), passando-se pelo planejamento/concepção/construção da edificação, também, considerando-se a vida útil da edificação (Tan, Shen \& Yao, 2011; Glavic \& Lukman, 2007; Williams \& Millington, 2004).

A proposta de imaginar a indústria da construção civil integrando estes aspectos surge num contexto mundial e enfrenta desafios sociais, econômicos e políticos atrelados a aspectos ambientais. Uma ênfase foi e ainda é dada na construção civil às tentativas de melhorar a gestão de resíduos e técnicas que provocavam efeitos nocivos ao meio ambiente e à saúde pública. Nas últimas duas décadas, foi possível observar também esforços significativos no âmbito da indústria da construção civil no contexto do controle do uso e da ocupação do solo (Song, 2014; Shen et al., 2004; Tam et al., 2007), do crescimento urbano (Zhang, Shen \& Scott, 2000), do fluxo de resíduos (Yeheyis et al., 2013) e do desempenho dos processos e produtos (Lamberts et al., 2008). Inclui-se nesta discussão até mesmo o envolvimento do setor com questões culturais e de equidade social. O ideal de responsabilidade social empresarial emerge neste cenário, como tentativa de 
integrar preocupações sociais e ambientais nas operações empresariais e nas suas relações com os stakeholders (CEC, 2001).

Deste modo, teóricos como Hill e Bowen (1997) propuseram resumir em quatro princípios a responsabilidade social de empresas da indústria da construção civil, o princípio (1) social; (2) econômico; (3) biofísico e (4) técnico, sendo que tais aspectos não devem ser trabalhados de maneira isolada. Estes princípios implicam em práticas que considerem o cumprimento das: a) responsabilidades ambientais/sociais (que não se resumem às legislações e às normas pois consideram também novas demandas); b) das exigências para um projeto que estruture a construção às melhores práticas, com otimização do custo versus desempenho (e que por isso impactem positivamente na competitividade da empresa); c) investimento em tecnologia e inovação - tanto em processos, como em produtos; d) formação de estruturas organizacionais para facilitar a conscientização de seus colaboradores, clientes internos e externos; e) elaboração de relatório vinculado a programas de monitoramento ambiental e metas relacionadas ao desempenho das edificações (Tan, Shen \& Yao, 2011; Kibert, 1994).

Tendo em vista estes fatores, um dos componentes da sustentabilidade organizacional já consolidado no mundo é a ecoeficiência (Dillick \& Hockerts, 2002; Jamali, 2006; Lins \& Zylbersztajn, 2010), cujo objetivo é equilibrar nas organizações três pilares (Triple Bottom Line - TBL): econômico, ambiental e social (Elkington, 1999). Cella-de-Oliveira e Munck (2014) consideram-na nas organizações como um processo capaz de induzir um novo modelo de gestão cujo objetivo é aliar o desenvolvimento econômico com o ambiental. Deste modo, coloca-se em evidência a preocupação com os impactos ambientais negativos das organizações e a promoção do uso racional de matéria-prima e energia (Dias et al., 2011).

Mais especificamente, Triana (2005) relata que a ecoeficiência na construção civil pode englobar categorias, tal como um entorno sustentável, ou seja, a consideração da infraestrutura existente que viabilize a implantação da edificação. Pode-se considerar o uso racional de recursos naturais que tem se traduzido em práticas que levam ao uso racional da água (aproveitamento de água da chuva, tratamento de esgoto, redução do consumo), da energia, de materiais (avaliação do ciclo de vida, preferência por materiais locais ou regionais). Ademais, a promoção da gestão de resíduos e a prevenção de emissões atmosféricas de gases de efeito estufa também podem ser incluídas nestas ações.

Deste modo, estas ações somente poderão ser potencializadas se as características do projeto forem flexíveis, o que promoveria novos usos (residenciais, comerciais, etc.) e novas possibilidades de modificação de layout. Tais características devem também promover a integração de sistemas, levando à promoção $e$ manutenção da qualidade ambiental interna da edificação - aspectos ligados à poluição do ar, ao conforto térmico, acústico e ao desempenho energético (Lamberts et al., 2008).

Em relação a estas temáticas, ressalta-se a significativa influência da construção civil nas discussões em torno das mudanças climáticas. Segundo estudos do Painel Brasileiro de Mudanças do Clima, modelos climáticos têm previsto cenários futuros para a região em estudo com uma elevação da temperatura média em torno de 2,5 a $3{ }^{\circ} \mathrm{C}$ até o final do século XXI (2071-2100) (PBMC, 2012). Ainda que contemplem incertezas nestas previsões (futuras emissões, limitações físicas dos modelos) é consenso de que as mudanças climáticas representarão um desafio no que diz respeito à obtenção de recursos naturais, à emissão de gases de efeito estufa e ao desempenho das edificações. Por isso, o Relatório do IPCC de 2014 (IPCC, 2014) identificou que a indústria da construção civil é um dos setores que, com alto grau de certeza, influencia nas emissões de gases de efeito estufa (GEE), sendo responsável por 19\% das emissões de GEE globais relacionadas ao uso de energia. Por consequência, deixa-se explícita a urgência de uma construção civil orientada para um alto desempenho dos novos edifícios e adaptação ambientalmente adequada dos já existentes (retrofit) (IPCC, 2014).

\section{NORMAS DE DESEMPENHO E SUAS IMPLICAÇÔES NA SUSTENTABILIDADE AMBIENTAL DAS EDIFICAÇÕES}

Um fator importante na rede de responsabilidades ambientais e que se insere no âmbito técnico é a discussão do desempenho das edificações. Um aspecto que não deixa de relacionar-se com sistemas sociais, econômicos e biofísicos. De modo que significativos trabalhos já foram realizados para desenvolver sistemas capazes de quantificar o desempenho de edifícios (Sorgato et al., 2014; Lamberts et al., 2008).

O conceito de desempenho de edificações vem sendo estudado desde a metade do século XX. Suas primeiras formulações e debates ocorreram a partir das questões apresentadas no segundo congresso do Council International for Building - CIB - (Conselho Internacional para Edificação), realizado em 1962 
(Kern, Silva \& Kazmierczak, 2014). Já em 1970, o CIB criou a comissão de trabalho CIB W60 - The Performance Concept in Building (O Conceito de Desempenho na Edificação) que tinha por objetivo estabelecer uma estrutura conceitual e tecnológica sobre o desempenho dos edifícios, que pudesse ser adotada em âmbito mundial. Atualmente, governos de países, tais como a Suécia, Suíça, Alemanha e Áustria, promovem grandes programas de financiamento, incentivando a aplicação de normas técnicas, tal como a Passivhaus, em vários países da Europa, encorajando mais especificamente neste caso, a otimização do desempenho térmico de residências. Tais incentivos resultaram em benefícios econômicos e ambientais (McLeod, Hopfe \& Rezgui, 2012; Lowe \& Oreszczyn, 2008).

$\mathrm{O}$ uso de instrumentos jurídicos baseados no conceito de desempenho é comum na Europa. Na Espanha, por exemplo, o Código Técnico das Edificações (CTE), em vigor desde 2007, estabelece o desempenho e durabilidade das edificações (Kern, Silva \& Kazmierczak, 2014). Trata-se de um programa de avaliação que estabelece metas de desempenho e maneiras de alcançá-las, sem forçar, entretanto, o uso de um método específico. Propriedades qualitativas e/ou quantitativas são consideradas e objetivos técnicos e gerenciais, possíveis de identificação, são estabelecidos (CTE, 2011). A relação desempenho e meio ambiente fica evidenciada logo no objetivo do Código ao descrever que visa garantir a segurança das pessoas, o bem-estar da sociedade, a sustentabilidade dos edifícios e a proteção do meio ambiente (CTE, 2011). Alguns aspectos, tais como segurança estrutural, prevenção a risco de incêndios, uso e acessibilidade, salubridade, eficiência energética e conforto acústico, são abordados. Destaca-se como positiva também a proposta de implantação gradual do CTE, que facilitou a adaptação de profissionais e fornecedores, além da criação de um meio de comunicação/integração entre a comissão responsável pela norma e os usuários (Kern, Silva \& Kazmierczak, 2014), uma plataforma na internet, por meio da qual os profissionais usuários da norma podem descrever suas dúvidas, críticas e contribuições.

Já no contexto brasileiro, avançou-se com a publicação da NBR 15575 (ABNT, 2013) que aborda questões, tais como ciclo de vida dos materiais, resíduos sólidos, uso racional de água e energia, sistemas construtivos (pisos, telhados etc.), vida útil de projeto e relação cliente-empresa (construtora e incorporadora). Assim como as demais normas de desempenho, a NBR 15575 (ABNT, 2013) expressa diversos requisitos e programas capazes de avaliar metas de desempenho. Desde então, o setor da construção civil passa pela intensificação das adaptações, buscando a qualidade dos processos construtivos e gerenciais envolvidos, além da própria edificação em si (produto final).

Vale ressaltar que nesta busca, encontra-se uma interface com a sustentabilidade ambiental das edificações (Silva et al., 2014), reconhecida em diversos estudos como ecoeficiência, ou seja, como a representação da integração entre sustentabilidades econômica e ambiental (Lins \& Zylbersztajn, 2010). Estudos confirmam que tal iniciativa tem sido responsável pelo aumento da competitividade no mercado da construção (Tan et al., 2015), diminuição do impacto ambiental negativo e de avanços no desempenho das edificações (Figura 1) (Varnäs, Balfors \& Faith-Ell, 2009; Tan, Shen \& Yao, 2011). Ademais, aspectos estratégicos são fundamentais de serem conhecidos, estabelecidos e avaliados, pois é a partir deles que as políticas e ações da empresa encontram embasamento e sustentação.

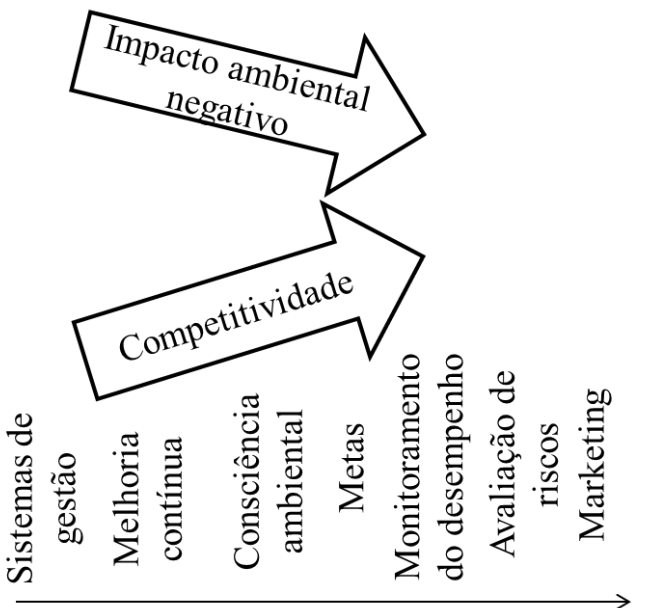

NBR 15575

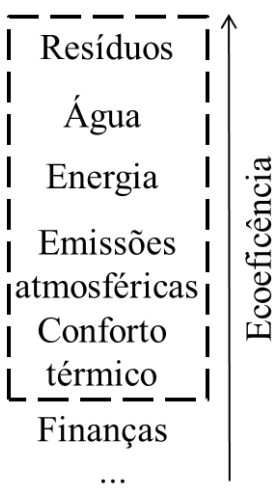

Estratégias de desenvolvimento ambiental

Figura 1 - Relações entre competitividade, impacto ambiental negativo e aspectos ligados à estratégia de negócios e à NBR 15575 (ABNT, 2013)

Fonte: Baseado em Tan, Shen \& Yao (2011) e ABNT (2013) 


\section{PERCEPÇÃO DE PROFISSIONAIS DA CONSTRUÇÃO CIVIL - DESEMPENHO E SUSTENTABILIDADE AMBIENTAL}

Estudos têm demonstrado o desafio da questão ambiental e do desempenho na perspectiva da percepção de profissionais envolvidos da cadeia produtiva da construção civil. Kern, Silva e Kazmierczak (2014) ao entrevistarem profissionais da construção civil a respeito da NBR 15575 (ABNT, 2013) concluíram sobre a necessidade de uma rediscussão da implementação integral da norma e, por fim, da adaptabilidade dos profissionais e fornecedores de materiais envolvidos.

Sousa e Ribeiro (2013) trazem a lume o desafio referente à percepção de ambiente natural e construído ao pesquisarem o perfil socioambiental de trabalhadores da construção civil no Distrito Federal. Verificou-se que a maioria dos entrevistados possui a percepção de que o ecossistema local sofre significativa redução devido à ocupação urbana. Já com uma abordagem ética e filosófica, Egito e Maia (2005) contribuem ao pesquisarem a percepção ambiental de engenheiro(as), arquitetos(as) e construtores(as) de João Pessoa (PB). Observou-se, nesta pesquisa, que o profissional em seu discurso se desvincula do ambiente natural, entendido de maneira reducionista como a "natureza intocada".

Catunda Pinto, Santos e Catunda (2015) analisaram também a percepção de profissionais da construção, associados ao Sinduscon/RN e atuantes no município de Parnamirim (RN), abordando aspectos específicos, referentes à gestão de resíduos da construção civil. A pesquisa mostrou que significativa parte dos entrevistados diz atender às exigências da legislação ambiental. Entretanto, 50\% das empresas percebem essa atividade como fonte de grande a moderado prejuízo, apesar de se interessarem em participar de programas de gestão ambiental (86\%). Farias e Teixeira (2002) apontam um quadro ainda mais comum, ao avaliar a percepção de microempresários em São Francisco (SE). Notou-se, neste caso, a concepção de política ambiental como aquela que se vincula somente a obrigações para com os órgãos públicos.

Considerando assim as fragilidades, os avanços e a pertinência do tema, analisou-se, por meio dessa pesquisa, a abordagem das construtoras e incorporadoras do município de Blumenau-SC, quanto aos conceitos de sustentabilidade inseridos na NBR 15575 (ABNT, 2013). Incluem-se na discussão, as categorias referentes à qualidade do ambiente construído, fornecendo elementos importantes para avaliar processos que visam um adequado desempenho e sustentabilidade da edificação (Reis \& Lay, 2006). Assim, pretendeu-se lançar possíveis perspectivas e oportunizar o compartilhamento de experiências, que são imprescindíveis para uma transformação positiva no setor (Zuo et al., 2012).

\section{MATERIAL E MÉTODOS}

A percepção das empresas construtoras e incorporadoras de Blumenau em relação aos requisitos da NBR 15575 (ABNT, 2013) e a sustentabilidade ambiental foi avaliada por meio de uma pesquisa do tipo exploratório, ocorrida nos meses de outubro e novembro de 2014. Este estudo foi realizado no município de Blumenau, em Santa Catarina, que possui uma população de 334.002 habitantes (IBGE, 2014).

\subsection{População de estudo}

A população em estudo considerou as 66 empresas associadas ao Sinduscon de Blumenau (Sindicato da Indústria da Construção de Blumenau) (Sinduscon, 2014). Foi realizada então uma triagem, excluindo-se empresas que não atuassem no município de Blumenau ou que não eram construtoras e incorporadoras. Também foram suprimidas empresas que não elaboravam os projetos ou que somente executavam a obra. Empresas que não responderam ao contato, via internet, telefone e/ou presencial, foram igualmente excluídas. Incluíram-se ainda, as empresas encontradas via pesquisa na internet, totalizando 13 construtoras e incorporadoras aptas a participar da entrevista.

Por ser um número reduzido de empresas qualificadas, optou-se por entrevistar a população inteira. Ao entrar em contato com essas 13 empresas, três delas não puderam participar da entrevista, devido à indisponibilidade de pessoal, sendo que a pesquisa foi realizada, então, com 10 construtoras e incorporadoras elencadas.

Destaca-se, ainda, que estas 10 organizações foram classificadas em duas categorias: (1) padrão de acabamento das edificações construídas e (2) porte da empresa, buscando-se investigar uma correlação entre essas informações e os resultados obtidos nas entrevistas. Considerou-se também que uma empresa possa 
trabalhar com um ou mais tipo de padrão de edificações, sendo que este padrão foi definido pelo próprio entrevistado. Já a respeito do porte da empresa, adotou-se a definição do Sebrae (2014) que considera que empresas da construção civil de pequeno porte possuem de 20 a 99 funcionários; de médio porte, de 100 a 499 funcionários e de grande porte, mais de 500 funcionários.

\subsection{Escopo das perguntas norteadoras da entrevista}

A abordagem metodológica da pesquisa é de caráter descritivo, realizando-se perguntas abertas, a fim de não limitar o entrevistado a respostas pré-estabelecidas (Chizzotti, 2000). As perguntas foram estruturadas em três níveis (Figura 2), iniciando-se com questões menos específicas (sustentabilidade, princípios profissionais), seguindo-se para as mais específicas (aspectos normativos). Abordou-se, deste modo, aspectos qualitativos e operacionais relacionados à percepção da construtora e/ou incorporadora sobre os requisitos da NBR 15575 e a sustentabilidade ambiental.

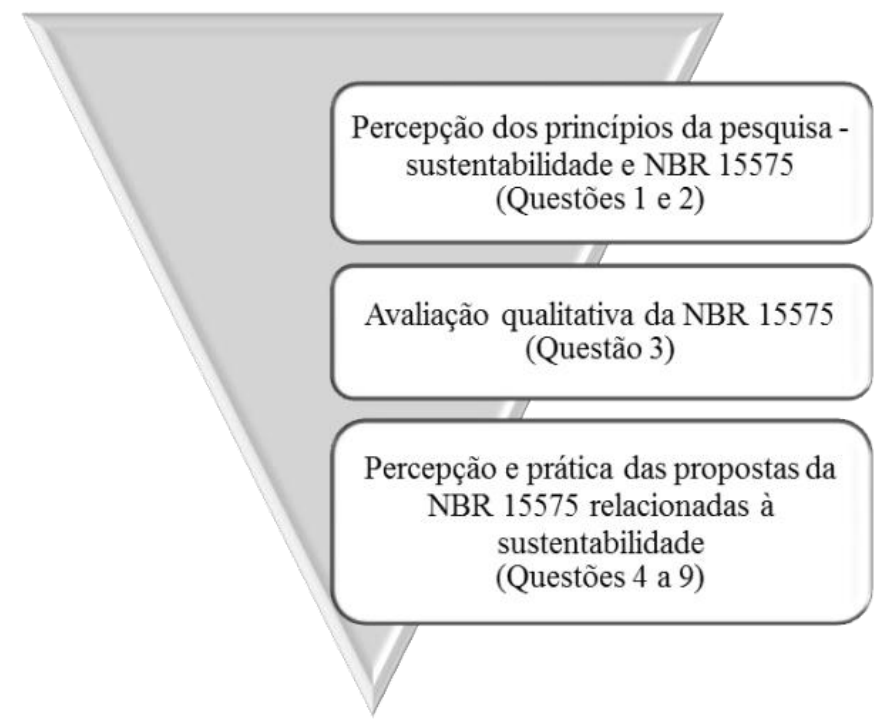

Figura 2 - Estrutura das perguntas norteadoras da entrevista aplicada às construtoras e/ou incorporadoras de Blumenau, SC, sobre a NBR 15575 (ABNT, 2013)

Fonte: Autores (2014)

A primeira questão colocada ao entrevistado das empresas foi "Como o princípio da sustentabilidade influencia o seu exercício profissional?" que tinha por objetivo introduzir o tema para o entrevistado e analisar as "palavras-chaves" utilizadas para se referir à sustentabilidade ambiental. Esta questão poderia também, facilitar o entendimento das respostas seguintes relacionadas, sobretudo, à sustentabilidade ambiental das edificações.

Em seguida, perguntou-se ao entrevistado se ele conhecia ou não a NBR 15575, e como ele a descreveria. Nesta questão, o objetivo era que o entrevistado descrevesse a norma com suas próprias palavras, e fosse verificado assim o seu entendimento a respeito do documento, cujo objetivo é estabelecer requisitos e critérios de desempenho às edificações habitacionais (ABNT, 2013).

Na terceira questão, "Que impactos (negativos e positivos) a aplicação da NBR 15575 traria para as construções da empresa na qual você trabalha?", tinha o intuito de observar as modificações que as construções da empresa sofreram/sofreriam com os requisitos da norma. Considerando que o contexto atual é de variados conflitos e avanços em relação à norma de desempenho (Sorgato et al., 2014; Kern, Silva \& Kazmierczak, 2014; Lorenzi, 2013).

A quarta questão questionava sobre o impacto da NBR 15575 na sustentabilidade das edificações, objetivando analisar se existe ou não a percepção de que os requisitos da norma podem tornar-se além de um diferencial no mercado (imagem, relação com cliente etc.), um modo também de prevenir retrabalhos, desperdícios e de garantir a qualidade. Ressalta-se que estes aspectos podem ser diretamente ligados à sustentabilidade ambiental (Carvalho \& Sposto, 2012).

As três questões que seguiam, abordavam diretamente as recomendações da NBR 15575 sobre o desempenho e a sustentabilidade da edificação. Sendo que na quinta e sexta foi perguntado se, "Na escolha 
dos materiais utilizados, é levado em consideração o ciclo de vida dos mesmos? Opta-se por utilizar materiais produzidos na região?" e se "Existe uma política de racionalização de água e energia no canteiro? Qual? Como é feita? Quais são as vantagens e dificuldades?". Intencionava-se verificar as medidas adotadas pela empresa para a racionalização de recursos e analisar se existe a percepção de que a economia de recursos energéticos e naturais representa um impacto econômico e ambiental positivo. Vale ressaltar que estes aspectos técnicos são abordados na NBR 15575 (ABNT, 2013) no item 18.3.

Já a sétima questão aferiu se "Existe um sistema de gestão de resíduos sólidos no canteiro? É viável? Por quê? Qual a importância dele?" e objetivou verificar se a gestão de resíduos da construção civil é percebida como um investimento ou uma alternativa inviável. Sobre a temática a NBR 15575 (ABNT, 2013, p.32) descreve que "[...] durante a construção, deve-se implementar um sistema de gestão de resíduos no canteiro de obras, de forma a minimizar sua geração e possibilitar a segregação de maneira adequada para facilitar o reuso, a reciclagem ou a disposição final em locais específicos."

Na penúltima pergunta, questionou-se se a vida útil de projeto (VUP) é considerada nos projetos, visando saber se as empresas adotam esse instrumento em seus projetos, e se não, qual a justificativa. A questão é relevante, pois trata da relação cliente-construtora e está intimamente ligada com a economia de insumos e a sustentabilidade ambiental. A NBR 15575 (ABNT, 2013) não deixa efetivamente explícita esta última relação, mas sem dúvidas deixa-se implícito tal fator ao recomendar a "[...] minimização de custos de operação e manutenção." (ABNT, 2013, p.43), ou seja, a minimização do impacto ambiental negativo pela redução do consumo de matéria e energia.

A última questão "A construtora elabora um Manual de Uso, Operação e Manutenção (e de áreas comuns) para os clientes? Que importância há no fornecimento dele?" objetivava verificar se este documento é percebido como uma ferramenta importante para uma gestão sustentável da edificação e se ele também possibilita melhoras na relação usuário-construtora. Caso o manual não fosse fornecido, procurou-se levantar as causas, considerando tratar-se de uma ferramenta fundamental também para que se atinja a vida útil de projeto adotada pelos profissionais (Santos et al., 2014).

\subsection{Análise dos dados}

Adotou-se o método proposto por Mattos (2005), de análise semântico-pragmática. O autor sugere que a análise de dados não se prenda apenas ao significado das palavras contidas nas respostas, mas sim, que se expanda para um sentido mais amplo, analisando o contexto inteiro no momento da entrevista. Implica assim, também em observar as reações do entrevistado e a postura dele durante as respostas. Além disto, foi considerado o fenômeno descrito pelo mesmo autor como "resposta retardante" que significa que muitas das perguntas podem ser respondidas complementarmente em questionamentos posteriores. "Palavras-chaves" também foram consideradas na análise dos discursos, possibilitando a contextualização de significados e percepções (Mattos, 2005; Gil, 2010).

\section{RESULTADOS E DISCUSSÃO}

\subsection{Caracterização das empresas entrevistadas}

Todas as empresas participantes são de pequeno (oito) ou médio porte (duas) conforme a classificação adotada, com um padrão das obras se distribuindo entre o baixo, alto e médio, sendo o médio no qual se contempla o maior número de empresas (Tabela 1). Cabe recordar que o padrão da obra foi estabelecido pelo próprio entrevistado (podendo ser mais de um) e que diz respeito ao acabamento das edificações.

Tabela 1 - Padrão da construção em função do porte da empresa.

\begin{tabular}{c|c|c|c}
\hline Porte da empresa & Pequena & Média & Grande \\
\hline Padrão das obras & 3 & 1 & 0 \\
Alto & 7 & 2 & 0 \\
Médio & 4 & 1 & 0 \\
\hline
\end{tabular}

Fonte: Autores (2014) 


\subsection{Percepção de princípios}

A questão sobre como a sustentabilidade ambiental influencia o exercício profissional do entrevistado foi respondida de imediato por três entrevistados, enquanto sete dos dez necessitaram de um lapso de tempo para respondê-la (Figura 3). Destes sete, dois não expressaram um entendimento sobre sustentabilidade, enquanto os outros cinco abordaram apenas alguns aspectos importantes e medidas a serem adotadas, não sendo possível, entretanto, expressar um conceito claro e objetivo. Já dos três entrevistados que responderam de imediato a pergunta, um não deixou claro seu entendimento, e dois compreendiam o conceito. Um deles, inclusive, fez uma citação aproximada do conceito de desenvolvimento sustentável do relatório de Brundtland (1991), respondendo que "[...]devemos guardar hoje para que os filhos e netos possam usufruir dos recursos no futuro".

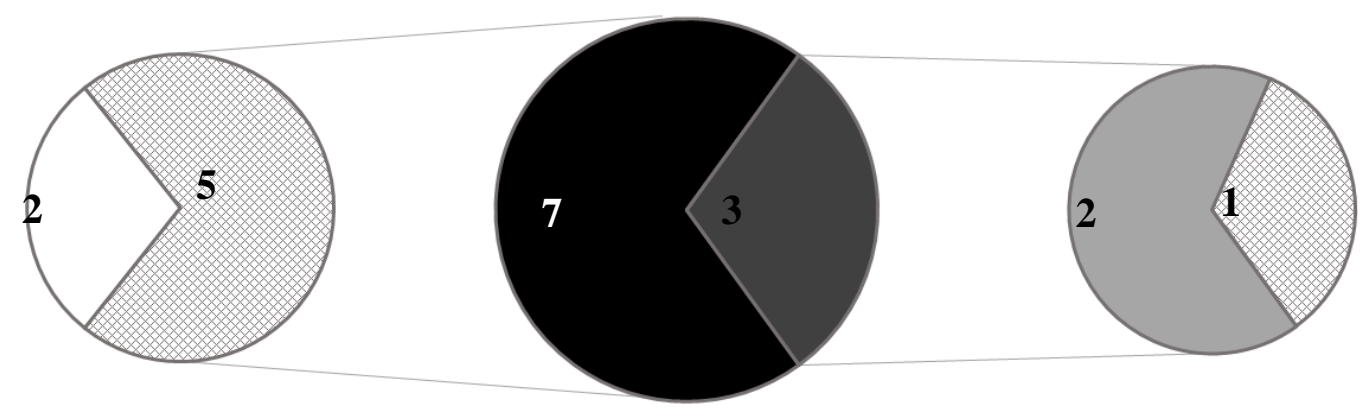

demorou para formular uma resposta; Não existe o entendimento;

Não demorou para formular uma resposta;

Existe o entendimento; Faltou clareza quanto à sustentabilidade ambiental.

Figura 3 - Entendimento de sustentabilidade dos entrevistados ( $\mathrm{n}^{\mathrm{o}}$ de respostas)

Fonte: Autores (2014).

Nesta questão, cabe destacar que, apesar de diversas definições para a sustentabilidade que abordam uma gama de ações, processos e produtos (Glavic \& Lukman, 2007; Williams \& Millington, 2004), e apesar dos numerosos esforços concentrados pelo setor privado, a sustentabilidade ambiental na engenharia não raras vezes é deslocada a um segundo plano, e não percebida como interconectada com demais aspectos gerenciais e operacionais (Jones, Michelfelder \& Nair, 2015).

Percebeu-se isto também em relação aos principais termos usados para tratar de sustentabilidade. Como a questão perguntava sobre a influência no exercício profissional do entrevistado, registrou-se que os participantes da pesquisa citaram pontos referentes a medidas adotadas pelas empresas (Figura 4). O termo mais citado foi a "obrigatoriedade", relacionando as medidas sustentáveis ambientalmente a apenas questões normativas/legais. Essa percepção talvez seja reforçada no contexto local considerando o fato de que realmente alguns temas voltados à sustentabilidade, como aproveitamento de água da chuva, tratamento de resíduos etc., são contemplados por leis. No município em estudo, um exemplo seria o caso da Lei Complementar municipal $n^{o} 691$ (Blumenau, 2008) que estabelece que edificações residenciais com mais de $750 \mathrm{~m}^{2}$ de área construída devem dispor de um sistema de aproveitamento da água de chuva.

Destaca-se ainda que o termo "obrigação" foi citado por entrevistados de três pequenas empresas e por um de uma empresa de porte médio, o que pode levar a crer que em empresas menores há uma resistência maior a estas mudanças (Silva Junior, 2014). Lucena, Schneider e Leydens (2010) afirmam que, muitas vezes, gerentes de obras são encarregados de conseguir o produto apenas nos limites do custo e dentro do cronograma, sem incluir aspectos relacionados à sustentabilidade ambiental (exceto quando se percebe estas questões diretamente relacionadas). 


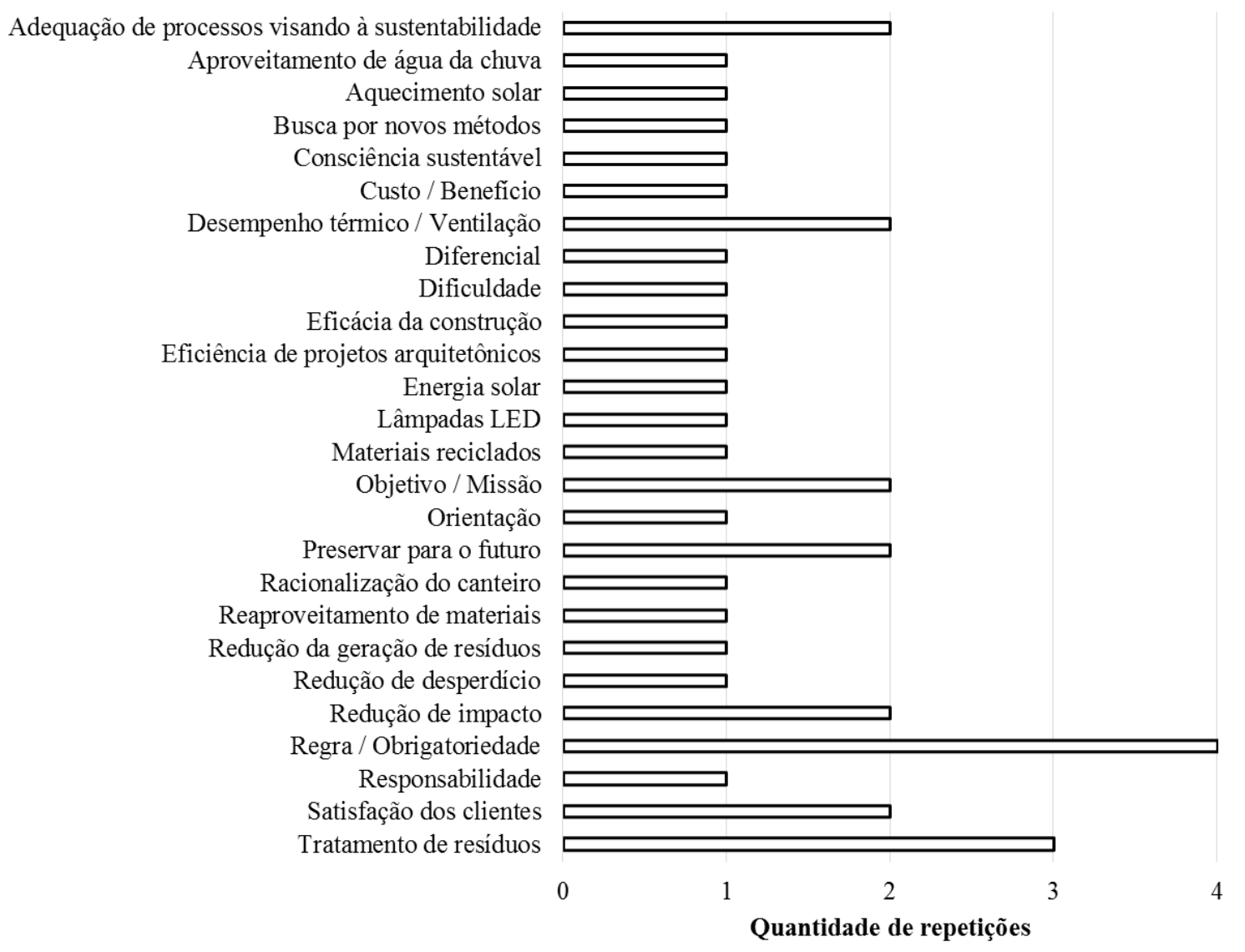

Figura 4 - Palavras-chave utilizadas para tratar de sustentabilidade ambiental no exercício profissional Fonte: Autores (2014)

Perceber-se como inserido em uma rede solidariamente dependente trata-se de um desafio a ser incorporado no exercício profissional de gestores da construção civil desde a formação acadêmica (Lozano \& Lozano, 2014) e até mesmo em pequenos cursos de atualização (Kern, Silva \& Kazmierczak, 2014).

Aliás, ao contrário dos processos de implantação de normas de desempenho em países europeus, o processo de implantação da NBR 15575 carece de um programa mais estruturado e abrangente voltado ao acompanhamento e formação dos profissionais no que concerne aos aspectos envolvidos. Até a realização desta pesquisa, o único instrumento oficial de contato entre os responsáveis pela norma e os demais atores envolvidos foram cursos promovidos pela Caixa Econômica Federal (Kern, Silva \& Kazmierczak, 2014). Entretanto, apenas isto não é suficiente. Afinal, qual instrumento que há e que possibilita a integração entre usuários da norma, fornecedores, poder público e a comissão responsável pela NBR 15575? Acredita-se que a ausência de tal estrutura fomente a percepção de obrigatoriedade (em contraposição à proatividade) para aspectos importantes para a própria organização e sua competitividade no mercado.

Ao passo que também se entende que a realidade das construtoras e incorporadoras submetidas à normativa é complexa. Mas justamente este tipo de instrumento integrador pode ser capaz de gerar um feedback das distintas realidades, e enriquecer uma discussão, inclusive a respeito do que se pode exigir na realidade particular de, por exemplo, uma empresa de pequeno porte. Seria de se esperar que elas, as empresas de pequeno porte, encarassem muito mais como uma obrigação, ensaios específicos e relativamente caros de verificação do conforto térmico? Seriam também delas os mesmos fornecedores das grandes empresas?

Estariam os fornecedores, assim, adaptados e integrados a NRB 15575? Lançam-se estes questionamentos de modo a trazer à luz o que se revelou na percepção dos entrevistados: a urgente necessidade de integrá-los, dando condições necessárias para que todos os atores envolvidos satisfaçam pertinentes demandas ambientais e sociais.

Um aspecto também muito citado foi o "tratamento de resíduos", revelando uma preocupação que as empresas têm em reduzir, reutilizar e reciclar ou encaminhar para aterros apropriados os resíduos gerados na obra. Essas citações corroboram com os resultados obtidos, posteriormente, na sétima pergunta, que aborda o 
tema "gestão de resíduos". O tratamento de resíduos tem sido cada vez mais percebido como um processo que reconhece positivamente o resíduo como matéria-prima, mas que exige do gestor uma abordagem técnica para reduzir os riscos de contaminação ambiental.

Além disso, a sustentabilidade como estratégia organizacional também se destacou nas entrevistas, incorporadas no conceito de missão, visão, objetivo, orientação, satisfação do cliente, revelando que tais organizações não consideram a possibilidade de que a sustentabilidade ambiental não esteja estruturada nas estratégias de negócio.

Na segunda questão, todos os entrevistados alegaram conhecer a NBR 15575 (ABNT, 2013). No entanto, apenas $30 \%$ deles revelou um conceito efetivo a partir do que a própria norma define. Esse resultado se deve provavelmente porque muitos alegaram já ter ouvido falar da norma, mas não a conheciam profundamente. Quatro dos entrevistados inclusive citaram a norma como sendo uma norma de sustentabilidade. Entretanto, mesmo o termo estando direta e positivamente ligado ao desempenho, sabe-se que este não é o escopo da normativa. Inclusive, um dos entrevistados desenvolveu uma descrição plausível da norma, mas considerou-se falta de clareza do entrevistado devido ao fato de achar que se tratava de uma norma de sustentabilidade e não especificamente de desempenho.

Baumgartner (2009) ao afirmar ser necessária uma mudança na cultura organizacional para que se internalizem mudanças efetivas nas práticas de empresas, reforça a necessidade de geração e promoção do conhecimento. Tendo sido verificado que o conhecimento sobre a NBR 15575 foi abaixo do esperado, revela-se um desafio a ser superado no que concerne à formação profissional. $\mathrm{O}$ que revela a necessidade de criar, como o que ocorre na Espanha (CTE, 2011), um canal de comunicação e integração de profissionais, fabricantes/fornecedores de materiais, empresas construtoras/incorporadoras, poder público e por fim os clientes (usuários da edificação), tendo em vista que esta cadeia será e já está constantemente pressionada por fatores relacionados à economia (nas mais diversas escalas) e às mudanças climáticas (Tan et al., 2015).

Já os impactos positivos e negativos que a aplicação da norma traz/traria para as construções foram traduzidos pelas vantagens e desvantagens citadas pelos entrevistados e a frequência de citação de cada item (Figura 5).

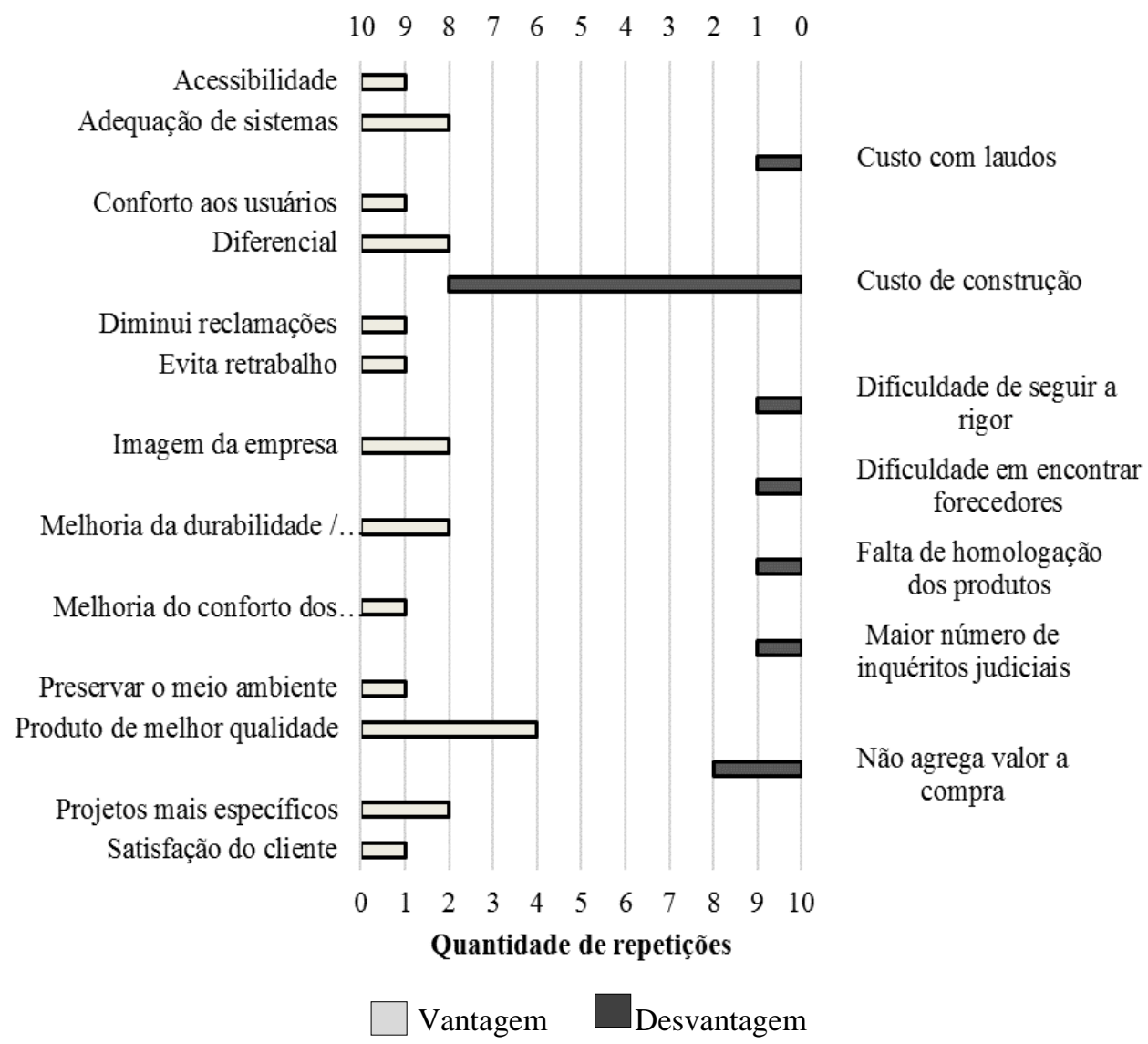

Figura 5 - Vantagens e desvantagens da aplicação da NBR 15575 (ABNT, 2013)

Fonte: Autores (2014) 
Como vantagem, destaca-se a melhoria da qualidade do produto, citada por $40 \%$ dos entrevistados. Um fato que deve ser evidenciado, é que todos os que afirmaram uma melhoria na qualidade das edificações, trabalham em empresas que possuem empreendimentos de baixo e/ ou médio padrão. Deste modo, as recomendações da NBR 15575 teriam um maior impacto positivo em edificações de baixo e médio padrão, se comparado aos empreendimentos de alto padrão.

O aspecto mais citado como desvantagem foi o custo da construção (80\%) que se revelou estar relacionado ao padrão da obra, resultado corroborado por Kern, Silva e Kazmierczak (2014) que, ao entrevistarem arquitetos brasileiros, relataram que os profissionais percebem que a NBR 15575 (ABNT, 2013) provoca um aumento nos custos da edificação por dois motivos: maior tempo demandado para a elaboração de projetos e maior tempo de capacitação/preparo dos profissionais e dos fornecedores de materiais.

Esta percepção é comum em cenários de mudança e novas exigências e deve ser considerada no processo de implantação da norma. Por exemplo, no caso do Código Técnico das Edificações espanhol, alguns requisitos foram sendo exigidos de maneira gradual, ao passo que um amplo investimento em formação e comunicação foi dado com o intuito de preparar o mercado de trabalho (para os desafios referentes a custos, produtividade, capacitação, desempenho da edificação e sustentabilidade ambiental) (Kern, Silva \& Kazmierczak, 2014).

Nota-se que $80 \%$ dos entrevistados citaram a necessidade de adaptar-se a alguns requisitos da norma devido ao aumento do custo global, ou seja, do produto final. Um dos entrevistados citou que a empresa já havia feito um levantamento, e que nas suas construções, esse aumento seria em torno de 3 a $4 \%$. Dentre os entrevistados que não citaram o custo, um trabalha em uma empresa de médio porte e com padrão médio das obras, e outro em uma empresa de pequeno porte, mas com obras de médio ou alto padrão. Todos com obras de pequeno porte ou empresas de pequeno porte perceberam significativamente a elevação dos custos devido aos requisitos da NBR 15575 (ABNT, 2013).

Silva Junior (2014) também descreve a preocupação em relação aos requisitos de certificações ambientais, sobretudo às construtoras e incorporadoras pequenas com obras de padrão baixo e/ou médio. Verificou-se que elas são as que mais percebem os impactos da norma de desempenho e, consequentemente, suas exigências a respeito da sustentabilidade ambiental. A partir da percepção avaliada nesse estudo, reforça-se a necessidade de atentar-se para as organizações de pequeno porte, visto que os requisitos de desempenho e sustentabilidade impactam negativamente mais sobre elas do que em empresas maiores.

\subsection{Percepção qualitativa da NBR 15575 e de seu impacto na sustentabilidade das edificações}

Questionando-se "Do ponto de vista da engenharia/arquitetura, como você avalia os requisitos exigidos pela NBR 15575 e o seu impacto na sustentabilidade das edificações? Um obstáculo? Um benefício? São incompatíveis com a prática comum (utópicos)?”, notou-se certa dificuldade dos entrevistados de associarem a norma com a sustentabilidade. O que pode ser percebido, é que os entrevistados falavam da norma de um modo geral, e foram todos muito breves na sua resposta, sendo que o aspecto mais citado foi a necessidade de adequação de processos para atender à norma, ou seja, a questão da obrigatoriedade (Figura 6).

Adequação de processos para atender a norma Aproveitamento de água da chuva

Custo
Eficiência de projetos arquitetônicos
Energia solar
Manutenção
Redução da geração de resíduos
Regra / Obrigatoriedade
Satisfação dos clientes

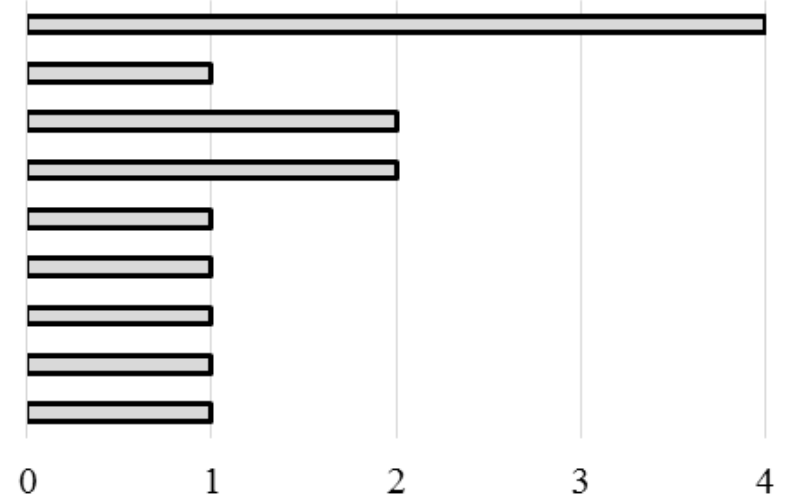

Quantidade de repetições

Figura 6 - NBR 15575 (ABNT, 2013) e impactos na sustentabilidade das edificações 
Fonte: Autores (2014)

Nota-se, que alguns termos utilizados na primeira questão (específica sobre sustentabilidade ambiental), até foram repetidos nesta pergunta (Adequação de processos, aproveitamento de água da chuva, eficiência de projetos arquitetônicos, energia solar, redução da geração de resíduos, regra / obrigatoriedade, satisfação dos clientes), porém, na primeira questão foram citados bem mais pontos que os entrevistados acabaram não associando à norma.

Este fato remete aos resultados da primeira pergunta, indicando que poucos entrevistados têm um conceito formado sobre sustentabilidade ambiental. Um dos entrevistados inclusive alegou que a norma não tinha influência na sustentabilidade e que ela somente estava associada à satisfação do cliente. Dois entrevistados acreditam que a norma tem itens relevantes, mas alguns devem ser reavaliados e aprimorados. Um dos entrevistados não quis responder a questão, pois alegou ter pouco conhecimento da norma.

Percebe-se, então, que os entrevistados consideram os requisitos da norma ainda mais associados a obrigações e elevação de custo, do que avanços na sustentabilidade ambiental da edificação. Jones, Michelfelder e Nair (2015) ao versarem sobre o tema relatam que a sustentabilidade ambiental é necessária às obras de engenharia e muitos engenheiros civis a consideram num projeto. Contudo, no caso dos entrevistados e diante das respostas obtidas, não pareceu claro um reconhecimento do termo, muito menos da abordagem de sustentabilidade organizacional que busca otimizar exigências econômicas, ambientais e sociais próprias e dos stakeholders (Lins \& Zylbersztajn, 2010; Van Kleef \& Roome, 2007).

Estes aspectos devem ser trabalhados de modo que políticas de melhoria no setor não se resumam a instalação de quadro normativo, revelando-se políticas reducionistas. É importante reconhecer que há demandas a serem supridas do ponto de vista da formação dos profissionais e capacitação de fornecedores/fabricantes às exigências de desempenho e sustentabilidade ambiental. Por isso, tais desafios devem considerar que a normatização no setor se trata de um processo e não de um produto pronto e acabado.

\subsection{Prática das propostas da NBR 15575 relacionada à sustentabilidade das edificações}

A escolha de materiais foi avaliada, visando detectar se a construtora considera o ciclo de vida dos mesmos e se opta por utilizar materiais da região. Constatou-se que $60 \%$ dos entrevistados afirmaram que a empresa leva em conta o ciclo de vida útil dos materiais sempre, com $40 \%$ respondendo "às vezes ou não ficou claro" (Figura 7).

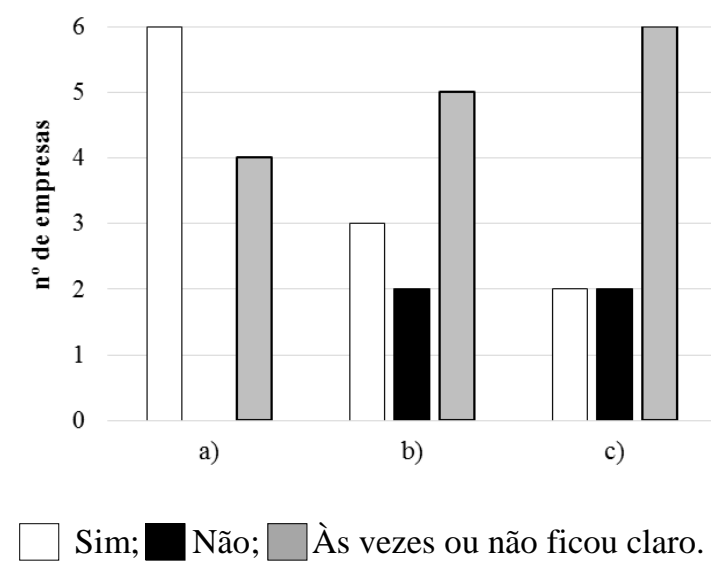

Figura 7 - Aspectos levados em consideração na escolha de materiais: a) É levada em consideração a análise do ciclo de vida dos materiais?; b) Priorizam materiais da região?; c) Percebe-se como vantajosa a utilização de materiais da região?

Fonte: Autores (2014)

Bremer et al. (2013), ao entrevistarem 25 profissionais da construção civil da região metropolitana de Belo Horizonte, chegaram a um resultado semelhante, ao constatar que $80 \%$ dos profissionais reconhecem que buscam materiais que contribuem para sustentabilidade ambiental da obra. Quanto à utilização de materiais da região, apenas três empresas alegaram fazê-lo. Neste quesito, as empresas parecem buscar por 
tecnologias e materiais de qualidade, que atendam às exigências dos usuários e do orçamento previsto. Se o fornecedor da região atender às suas "expectativas", opta-se por ele, caso contrário, buscam-se materiais inclusive importados.

Destacadamente nesta pergunta não se registraram respostas que colocassem à tona desafios concernentes à adequação de fornecedores de materiais, ou seja, a adequação voltada ao atendimento das "expectativas". Em outros estudos que realizaram entrevistas com profissionais da construção civil este aspecto foi ressaltado, visto que não existe um programa oficial de incentivo à adaptação dos principais fornecedores de materiais com os requisitos da NBR 15575 (Silva et al., 2014; Kern, Silva \& Kazmierczak, 2014).

Referente à percepção da vantagem de utilização de materiais da região, $60 \%$ dos entrevistados não deixou clara essa percepção. Tendo em vista que em perguntas relativas à sustentabilidade, questões, tais como mudanças climáticas e poluição atmosférica, não foram consideradas/mencionadas, acredita-se, por isso, que haja mesmo uma dificuldade em perceber as vantagens socioambientais de materiais provenientes da região.

Recentemente na $21^{\mathrm{a}}$ Conferência das Partes (COP-21) da Convenção do Clima das Nações Unidas, ocorrida de 30 de novembro a 11 de dezembro de 2015, o setor da construção civil não passou despercebido, considerando-se que, aproximadamente, 30\% das emissões globais de GEE provêm do setor (UNEP, 2009). Os processos de obtenção de matéria-prima e execução das obras (gasto de energia em demasiado) são os principais fatores para o significativo impacto negativo do setor. Não por acaso, dois pontos pertinentes também foram contemplados nas discussões da COP-21: o desmatamento e as fontes energéticas (CBIC, 2015).

No caso brasileiro, a Comissão de Meio Ambiente da Câmara Brasileira da Indústria da Construção já tem desenvolvido políticas de incentivo ao uso de madeira certificada e geração fotovoltaica de energia nos tetos de residências (CBIC, 2015). Estas ações evidentemente não esgotam as questões relacionadas à emissão dos GEE, contudo, representam um ponto de partida fundamental. Assim como são as recomendações e exigências da NBR 15575 que incorporam parte destas questões na abordagem do ciclo de vida útil dos materiais e da vida útil projetada da própria edificação.

Ressalta-se ainda que dentre os que deixaram claro ver vantagens em utilizar materiais da região, um trabalha em uma empresa que usa os fornecedores locais, então, por isso, observa com mais facilidade as vantagens que isto acarreta. Outro entrevistado alega enxergar a importância, mas afirma que a empresa acredita ser mais relevante a quantidade de manutenção que um produto pode gerar.

Destaca-se que o impacto negativo de materiais da construção pode ser significativamente reduzido também pela substituição de recursos naturais finitos e pelo uso de resíduos. Isto estimularia a concorrência entre os fabricantes a desenvolver produtos reciclados/reutilizados e incentivar o uso das certificações ambientais (Bribián, Capilla \& Uson, 2011). Reconhece-se como fundamental tentar reintroduzir materiais reciclados ou reutilizáveis em novas edificações, possibilitando, deste modo, reduzir impactos ambientais negativos (Reid \& Houston, 2013) e otimizar a relação entre extração de matéria-prima/emissões de GEE. O fato também de os entrevistados não terem claras as vantagens de se utilizar materiais da região (como, por exemplo, a redução na emissão de gases poluentes durante o transporte) demonstra que este não é o fator decisivo na escolha do produto.

A sexta questão, sobre a racionalização de água e energia, evidenciou vários avanços. Nove das dez empresas alegaram adotar medidas de uso racional de água. O entrevistado da única empresa que não o faz, alegou ser importante fazê-lo, mas como não impacta significativamente no custo, ainda não o fazem (Figura 8). Em relação ao uso racional de energia, $70 \%$ das empresas o realizam, sendo curioso observar que 10 dos $30 \%$ que não a fazem, também admitem não realizar o uso racional de água (Figura 8). 


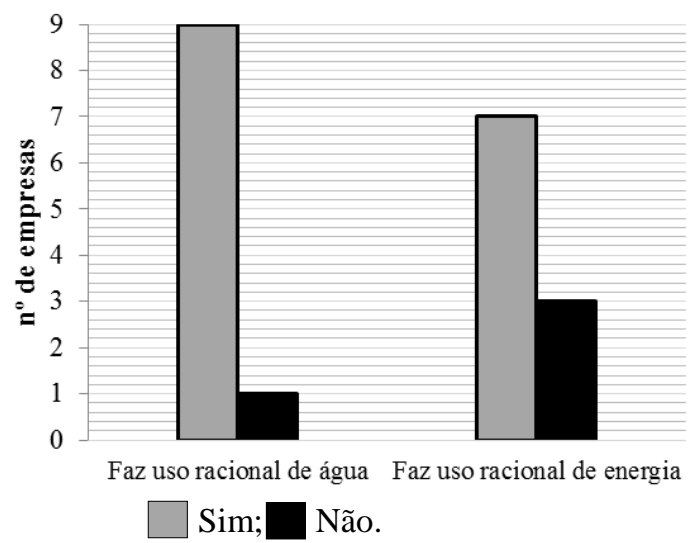

Figura 8 - Empresas que fazem uso racional de água e energia ( $\mathrm{n}^{\circ}$ de empresas). Fonte: Autores (2014)

Na Figura 9, foram listados os itens citados como medidas de uso racional de água e energia, bem como a quantidade de repetições dos termos citados pelos entrevistados.

$\begin{array}{llllllllllllll}10 & 9 & 8 & 7 & 6 & 5 & 4 & 3 & 2 & 1 & 0\end{array}$



Figura 19 - Medidas para fazer uso racional de água e energia

Fonte: Autores (2014)

Observa-se que o aproveitamento de água para fins não potáveis é a medida mais adotada dentre as empresas, sendo citada por $60 \%$ dos entrevistados. Como há uma lei municipal na área de estudo (Blumenau, 2008), este fato justifica a alta incidência desta medida, sendo relevante, uma vez que se percebe que as empresas realmente estão realizando e contribuindo positivamente para a sustentabilidade ambiental e econômica da edificação. Estudos relacionados à prática da construção civil local também relatam que esta medida é destacada como meio de promoção do uso racional da água (Bremer et al., 2013; Motta \& Aguillar, 2009). Porém, esta contribuição pode ser minorada, para não dizer-se prejudicada. Estudos, tal como de Uber (2015), demonstraram que, no município estudado, a eficiência de alguns reservatórios de água da chuva (residenciais) não chega aos $10 \%$.

Tal investigação salientou a necessidade de que, no mínimo, estes aspectos sejam esclarecidos ao cliente externo, sob risco de a tecnologia entrar em descrédito. Neste caso, não se trata de propor que sejam obrigatórios parâmetros mínimos de eficiência, considerando que, em determinadas realidades brasileiras 
(p.ex. semiárido brasileiro), a eficiência de um reservatório pode ser significativamente limitada por fatores naturais (Doss-Gollin, Souza Filho \& Silva, 2015). Trata-se, entretanto, de aplicar efetivamente os conceitos de estratégias de desenvolvimento sustentável (Tan, Shen \& Yao, 2011), de modo a esclarecer ao consumidor final o desempenho mínimo "esperado" do produto. Este princípio não se encontra explícito na NBR 15575 (ABNT, 2013), mas acredita-se ser de fundamental importância para uma relação transparente entre cliente, construtora e tecnologias sustentáveis.

Referente ao uso racional de energia, destacam-se duas medidas, uma estrutural, voltada ao uso de sensor de presença e outra não estrutural, voltada à educação ambiental (conscientização) dos funcionários. Nota-se que este último aspecto não foi tão marcante na questão referente ao uso racional de água. Salientase que este é um ponto fundamental e que deve ser fortalecido na promoção da redução do consumo de matéria e energia, tendo em vista os desafios inerentes à gestão ambiental do ambiente de trabalho (Sousa \& Ribeiro, 2013). Reid e Houston (2013) destacam esse ponto também (neste caso, em relação aos usuários da edificação) ao relatar que eles estão cada vez mais dispostos a tecnologias verdes e edificações sustentáveis, porém quando se trata de qualquer mudança comportamental a resistência é maior.

No tocante à gestão de resíduos da construção civil (RCC), todos os entrevistados alegaram se preocupar com os resíduos. Conforme observado, quatro dos entrevistados (Figura 10) citaram que é obrigatório fazer a gestão dos RCC, mas não mencionaram nenhuma legislação em específico.

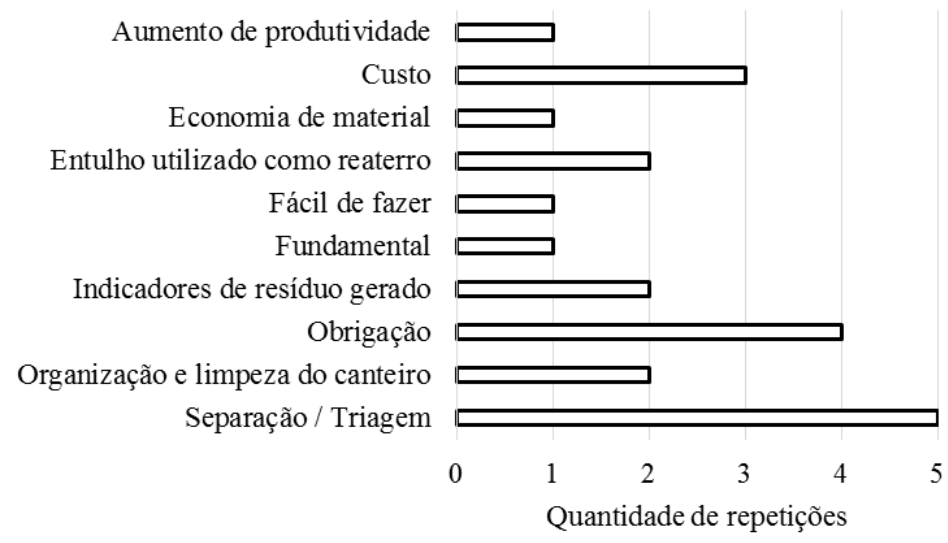

Figura 10 - Termos relacionados à gestão de resíduos da construção civil Fonte: Autores (2014)

O ponto mais citado foi a separação de resíduos e dentre os cinco entrevistados que afirmaram fazêlo, dois alegaram que a separação de resíduos é feita por classes, mas que a efetiva segregação dos materiais é feita fora da obra, por empresas especializadas em geri-los. Outros três alegaram que a separação do material reciclado já é realizada na fonte. Nesta questão, novamente o custo foi um dos principais aspectos mencionados, citando-se o gesso como exemplo de um material cuja disposição final é cara. Entretanto, pesquisas já apontam alternativas economicamente viáveis de reciclagem, e em 2011 o gesso foi reenquadrado pela resolução $n^{\circ} 431$ na classe B de resíduos da construção civil, ou seja, classificado como resíduo reciclável (Conama, 2011). Interessante notar que além de se ressaltar o custo, não houve menção ao que o Conseil International du Bâtiment considera como prioridade na gestão dos resíduos da construção civil (RCC): a redução na geração de resíduos (CIB, 2000), fator que novamente alia-se, em grande medida, ao comportamento dos colaboradores da empresa.

Neste aspecto, os métodos construtivos também influenciam e podem tanto prejudicar como beneficiar ações e programas que visem reduzir a geração de resíduos. Reconhece-se que, para a implantação de novos métodos, exige-se capacitação técnica e de investimento. Esta discussão já avança em países desenvolvidos, tais como Japão, Austrália, Estados Unidos, que adotam edifícios com paredes de concreto, light steel frame, light wood frame e até construção 3D por diversos fatores: economia de insumos, recursos financeiros, melhoria no desempenho térmico, acústico, agilidade do processo construtivo e diminuição de custos com mão de obra que, por muitas vezes, é escassa e cara (Carls, 2015; Nunes, 2011; Molina \& Calil Junior, 2010).

No que diz respeito à mão de obra, Gonçalves, Ito e Carvalho (2015), ao pesquisarem a percepção de 
arquitetos de todo o Brasil em relação aos RCC, observaram que, segundo os entrevistados, a principal limitação que as empresas encontram para reduzir a geração de resíduos é o desconhecimento do processo construtivo e a falta de metodologia para a minimização dos RCCs.Dois aspectos influenciadores também no desempenho das edificações.

Catunda Pinto, Santos e Catunda (2015), ao pesquisaram a percepção em relação aos RCCs de 14 empresas de Parnamirim, Rio Grande do Norte, verificaram que apenas 50\% possuíam alguma medida positiva no canteiro de obras. Neste sentido, vale destacar a importância da formulação de um plano municipal de gerenciamento dos resíduos da construção civil (Tessaro, Sá \& Scremin, 2012). Os dados obtidos nesta pesquisa reforçam ser fundamental a construção de uma política pública municipal integrada para o descarte e aproveitamento dos RCCs. Além do mais, segundo o Plano Municipal de Saneamento, prevê-se até 2030 uma Usina de Reciclagem de Resíduos da Construção Civil operada pelo Poder Público (Blumenau, 2009).

Outro aspecto pertinente e abordado também foi a vida útil de projeto (VUP). Neste caso, apenas um entrevistado revelou que não a considera, justificando o fato de ser difícil de estimar. Questionados quanto ao tipo de projeto no qual a VUP é considerada, todos foram unânimes ao responderem que a consideram apenas e exclusivamente no projeto estrutural. Quanto às medidas empregadas pelas empresas, citou-se o atendimento às normas de cálculo, a adequada adoção da resistência característica do concreto à compressão (fck), o respeito ao cobrimento segundo cada classe de agressividade e o cuidado com a relação água cimento $(\mathrm{a} / \mathrm{c})$.

Ainda sobre a VUP, um dos entrevistados comentou que no momento eles só possuíam obras anteriores à vigência da norma, e que nesses projetos ela não havia sido levada em consideração, mas nos projetos que estão em estudo a empresa já a está implantando. Outro entrevistado comentou também que nos novos projetos a empresa começaria a adotar em outros tipos de projeto, e não somente no estrutural. E um terceiro entrevistado mencionou que era difícil de fazer a consideração em outros projetos devido à falta de certificação dos produtos. Segundo ele, era necessário que as empresas começassem a fazer estudos para garantir a VUP dos produtos para que, assim, os projetistas a pudessem considerarem em seus projetos. Neste aspecto, observou-se que o sistema voltado à vida útil de projeto é percebido como burocrático e pouco claro, o que representa um desafio contínuo na gestão de sistemas de desempenho (Etges, Viana \& Formoso, 2014).

Integrado também a este tema, na última questão perguntou-se sobre o fornecimento do Manual de Uso, Operação e Manutenção para os usuários. Verificou-se que $20 \%$ dos entrevistados mencionaram não entregá-lo. Um deles alegou que as obras eram muito variadas (a empresa possui todo padrão de obra) e assim ficava difícil de padronizar o manual. Outro entrevistado comentou que a empresa está iniciando o processo de desenvolvimento do manual, porém, só o vê como um documento de divisão de responsabilidade entre a construtora e o cliente. Em outras palavras, nota-se que não se vincula o Manual de Uso, Operação e Manutenção para os usuários com o atendimento das condições necessárias para se atingir a VUP e muito menos com a sustentabilidade/desempenho/durabilidade da edificação.

Dentre as empresas que fornecem o manual, todos os entrevistados veem importância na entrega, mas três empresas apenas o têm como forma de se isentar de responsabilidades ou diminuir o contato pósobra. Trata-se de uma visão reducionista da Manual de Uso, Operação e Manutenção, diante da capacidade instrumental que ele possui para integrar a organização com o usuário, subsidiando assim a gestão da edificação pós-obra. Em outras palavras, o Manual pode servir de instrumento norteador para a manutenção das condições previstas no projeto que, por fim, promovem o desempenho/qualidade esperada. Neste sentido, Tannuri e Van Bellen (2014) reforçam que a clareza, o equilíbrio e a relevância das informações divulgadas podem auxiliar significativamente as organizações a aperfeiçoarem seus processos.

Considera-se como um avanço, o fato de que metade das empresas fornece o manual e reconhece o fato de ele conter aspectos fundamentais relacionados à conservação, manutenção e operação dos edifícios. Este ponto é bastante positivo, pois as construtoras e incorporadoras têm esse cuidado em explicitar os procedimentos necessários para manter a vida útil da edificação. Em contrapartida, 30\% dos profissionais afirmaram que o manual raramente é lido, ou seja, percebem que o usuário não participa ativamente na gestão de uso da residência. Esse aspecto merece destaque visto que a participação passiva do cliente na edificação poderá implicar em prejuízos no desempenho da edificação, tendo em vista que ele se encontra diretamente inserido na rede de construção/manutenção da vida útil da edificação. Deste modo, a qualidade ambiental e a vida útil da edificação podem ser potencializadas por meio das interações (experiências, feedback, benchmark, critérios) da construtora/incorporadora e dos usuários (Bonatto, Miron \& Formoso, 2011). 


\section{CONSIDERAÇÕES FINAIS}

A percepção do impacto da NBR 15575 na sustentabilidade da edificação é uma questão complexa de ser analisada entre os profissionais gestores de obras de construção civil. Por um lado, seria um equívoco afirmar que a percepção de ecoeficiência seja totalmente inexistente. Por outro, ela parece ser significativamente vinculada a apenas uma questão normativa, legal. Esta percepção, muitas vezes, demonstra-se como impeditiva para uma mudança organizacional mais profunda, possibilitando que "proativamente", novos negócios aliem desenvolvimento econômico e ambiental.

Neste sentido, verificou-se uma maior barreira para a aplicação dos aspectos abordados da NBR 15575 em construtoras e incorporadoras de pequeno porte, com obras de padrão baixo e/ou médio. Em consonância com outros estudos, essas organizações indicaram perceber um maior impacto no custo com as medidas da NBR 15575 abordadas na entrevista. Destaca-se também que apenas 30\% dos entrevistados conheciam a norma e seus aspectos primordiais para uma gestão da qualidade das edificações. Este fato indica a necessidade de integrar e articular ao tema, os mais diversos atores envolvidos na formação cognitiva dos profissionais, além dos próprios agentes da cadeia produtiva da construção civil.

Apesar destes resultados, observou-se que medidas são tomadas visando o uso racional de água e energia, bem como a gestão de resíduos. A consideração de vida útil de projeto ainda é pouco considerada e aplicada exclusivamente no projeto estrutural.O principal instrumento garantidor das condições de projeto (Manual de Uso, Operação e Manutenção) é utilizado de forma incipiente, segundo a percepção dos entrevistados. Por fim, concluiu-se que as empresas entrevistadas têm uma significativa consciência quanto à sustentabilidade ambiental do ponto de vista de suas práticas, porém não a percebem relacionada com aspectos de qualidade e desempenho das edificações.

Deste modo, considerando que este estudo limitou-se a percepção dos profissionais de engenharia, sugere-se que futuras pesquisas abordem a percepção dos demais atores envolvidos na cadeia produtiva (fabricantes/fornecedores de materiais, poder público, entidades de classe, sindicatos). Uma pesquisa quantitativa, objetivando analisar os processos aqui relatados e descritos pelos entrevistados, poderá também nortear novos avanços e abrir novas perspectivas capazes de responder aos desafios demandados pelas mudanças do clima.

\section{AGRADECIMENTOS}

Os autores agradecem à Coordenação de Aperfeiçoamento de Pessoal de Ensino Superior (CAPES) pela concessão da bolsa de mestrado ao primeiro autor.

\section{REFERÊNCIAS}

Associação Brasileira de Normas Técnicas. NBR 15575-1: Edificações habitacionais - Desempenho. Rio de Janeiro, 2013.

Baumgartner, R. J. (2009) Organizational culture and leadership: preconditions for the development of a sustainable corporation. Sustain. Dev. 17, 102-113.

Blumenau. Lei Complementar $n^{\circ}$ 691, de 29 de setembro de 2008. Institui o "Programa de conservação e uso racional de água" no município de Blumenau. Blumenau, SC, 2008. Disponível em: <https://www.leismunicipais.com.br/a/sc/b/blumenau/lei-complementar/2008/69/691/lei-complementar-n691-2008-institui-o-programa-de-conservacao-e-uso-racional-de-agua-no-municipio-de-blumenau>. Acesso em: 6 jul. 2015.

.(2009) Plano Municipal de Saneamento. Blumenau, SC. Recuperado em 20 out.2014, de: <http://www.samae.com.br/arquivos/Plano_de_saneamento.pdf $\rangle$.

Bonatto, F. S., Mirion, L. I. G., Formoso, C. T. (2011) Avaliação de empreendimentos habitacionais de interesse social com base na hierarquia de valor percebido pelo usuário. Ambiente Construído [online], 11(1), 67-83.

Boselli, T., Dunowicz, R. (2009) La calidad y la conservación de la vivienda social: bases para el aseguramiento de la sustentabilidad del hábitat. In: Encontro Nacional, 5. Encontro Latino-Americano sobre Edificações e Comunidades Sustentáveis, 3, Recife. 
Bremer, C. F., Oliveira, D. M., Lopes Junior, J. M., Oliveira, P. M. (2013) Avaliação das práticas de sustentabilidade adotadas em empreendimentos de construção civil de Belo Horizonte. Construindo, 5(1), 23-28.

Bribián, I.Z, Capilla, A.V., Usón, A.A. (2011) Life cycle assessment of building materials: Comparative analysis of energy and environmental impacts and evaluation of the eco-efficiency improvement potential. Building and Environment, 46 (5), 1133-1140.

Brundtland, Gro Harlem (org.)(1991) Nosso Futuro Comum. Relatório da Comissão Mundial sobre Meio Ambiente e Desenvolvimento. Tradução de Report of the World Commission on Environment and Development: Our Common Future (1987). (2 ed.) Rio de Janeiro: Editora da Fundação Getúlio Vargas, 430p.

Carls, B.(2015) Perspectivas da utilização das impressoras 3d na construção civil. (2015) Trabalho de conclusão de curso. Recuperado em 20 dez.2015, de: <http://www.bc.furb.br/docs/MO/2015/359599_1_1.pdf>.

Carvalho, M. T. M., Sposto, R. M. (2012) Metodologia para avaliação da sustentabilidade de habitações de interesse social com foco no projeto. Ambiente Construído [online], 12(1), 207-225.

Catunda Pinto, C. H., Santos, A. L., Catunda, A. C. M. M. (2015) Percepção da legislação ambiental, gestão e destinação final dos RCD - Resíduos da Construção e Demolição: um estudo de caso em Parnamirim/RN/Brasil. HOLOS, 2, 33-49.

CBIC - Câmara Brasileira da Industria da Construção. (2015) COP-21 amplia responsabilidade da construção civil na redução da emissão de gases de efeito estufa. Recuperado em: 23 dez, de: <http://www.cbic.org.br/sala-de-imprensa/noticia/cop-21-amplia-responsabilidade-da-construcao-civil-nareducao-da-emissao-de>.

CEC - Commission for the European Communities. (2001) Commission for the European Communities Green paper: promoting a European framework for corporate social responsibility. Brussels.

Cella-de-Oliveira, F. A., Munck, L. (2014) Uma proposta de mensuração da ecoeficiência a partir das competências organizacionais e do agir organizacional. Revista de Gestão Social e Ambiental, 8(1), 73-88.

Chizzotti, A.(2000) Pesquisa em ciências humanas e sociais. (4. ed.) São Paulo: Cortez, 164 p.

CIB - Conseil International du Bâtiment.(2000) Agenda 21 para a construção sustentável. Tradução de: Agenda 21 on sustainable construction. CIB Report Publication 237. EDUSP-USP, São Paulo, 131p.

CTE - Código Técnico de la Edificación. España. (2011) Recuperado em: 23 maio 2015, de: $<\mathrm{http}: / /$ www.codigotecnico.org $>$.

Conama. (2011) Resolução Conama n $n^{\circ} 31$, de 24 de maio de 2011. Altera o art. $3^{\circ}$ da Resolução no 307, de 5 de julho de 2002, do Conselho Nacional do Meio Ambiente, estabelecendo nova classificação para o gesso, Brasília, DF, 2011. Recuperado em 7 jul.2015, de: <http://www.mma.gov.br/port/conama/legiabre.cfm?codlegi=649>.

Dias, B. G., Munck, L., Bansi, A. C., Cella-De-Oliveira, F. A. (2011) Bases compreensivas da sustentabilidade organizacional: a proposição de uma estrutura conceitual (Framework). Seminário em Administração, São Paulo, SP, Brasil, 16.

Dillick, T., Hockerts, K. (2002) Beyound the business case for corporate sustentability. Business Strategy and the environment, 11, 130-141.

Doss-Gollin, J., Souza Filho, F. D. A., \& Silva, F. O. E. (2015) Analytic modeling of rainwater harvesting in the Brazilian Semiarid Northeast. Jawra Journal of the American Water Resources Association.

Egito, M. J. C., Maia, D. S. (2005) Percepção ambiental dos agentes da construção civil na cidade de João Pessoa - PB. In: Simpósio Nacional Sobre Geografia, Percepção E Cognição Do Meio Ambiente, 1, 2005, Londrina. Anais... Londrina: [s.n.], 2005, 1-14.

Elkington, J. (1999) Cannibals with forks: the triple bottom line of 21st century business. Oxford: Capstone Publishing Limited. 
Etges, A. P. B. S., Viana, D. D., Formoso, C. T. (2014) Diretrizes para a medição de desempenho de processo logístico em uma empresa de sistemas pré-fabricados que adota a filosofia Lean Production. Produto \& Produção, 15(4), 42-54.

Farias, J. S., Texeira, R. M. (2002) A pequena e micro empresa e o meio ambiente: a percepção dos empresários com relação aos impactos ambientais. Organizações \& Sociedade, 9(23), 1-20.

Gil, A. C.(2010) Métodos e técnicas de pesquisa social. (6. ed.) São Paulo: Atlas.

Glavic, P., Lukman, R. (2007) Review of sustainability terms and their definitions. J. Clean. Prod., 15, 18751885.

Gonçalves, P. H., Ito, A. P. N., Carvalho, D. C. G. (2015) A avaliação da perspectiva dos arquitetos na redução de resíduos na etapa de projeto arquitetônico. PARC Pesquisa em Arquitetura e Construção, 6(1), $16-25$.

Hill, R. C., Bowen, P. (1997) Sustainable construction: principles and a framework for attainment. Construction Management and Economics, 15(3), 223-239.

IBGE - Instituto Federal de Geografia e Estatística.(2014) Censo Demográfico - 2010. Recuperado em: 6 jul.2015, de: <http://cidades.ibge.gov.br/xtras/perfil.php?codmun=420240>.

IPCC - Intergovernmental Panel on Climate Change.(2014) Fifth assessment report (AR5). Recuperado em: 30 dez.2015, de: 〈http://www.ipcc.ch/pdf/assessment-report/ar5/wg3/ipcc_wg3_ar5_chapter9.pdf>.

Isaia, G. C., Ino, A.(2007) Materiais de construção civil e princípios de ciência e engenharia de materiais. São Paulo: Ibracon. 2v, il. +, 1 CD-ROM.

Jamali, D. (2006) Insights into the triple bottom line integration from a learning organization perspective. Business Process Management Journal, 12(6), 809-821.

Jones, S. A., Michelfelder, D., Nair, I. (2015) Engineering managers and sustainable systems: the need for and challenges of using an ethical framework for transformative leadership. J. Clean. Prod. (no prelo).

Kern, A. P., Silva, A., Kazmierczak, C. S. (2014) O processo de implantação de normas de desempenho na construção: um comparativo entre a Espanha (CTE) e Brasil (NBR 15575/2013). Gestão e Tecnologia de Projetos, 9(1), 89-101.

Kibert, C. J. (1994) Establishing principles and a model for sustainable construction. In: First international conference of CIB TG 16 on sustainable construction, Tampa, Florida, 6-9 November. Proceedings..., Florida.

Lamberts, R., Triana, M. A., Fossati M., Batista, J. O. (2008) Sustentabilidade nas edificações: contexto internacional e algumas referências brasileiras na área. Florianópolis: Universidade Federal de Santa Catarina (UFSC).

Lins, L., Zylbersztajn, D. (2010) Sustentabilidade e geração de valor: a transição para o século XXI. Rio de Janeiro: Elsevier.

Lorenzi, S. L. (2013) Análise crítica e proposições de avanço nas metodologias de ensaios experimentais de desempenho à luz da ABNT NBR 15575 (2013) para edificações habitacionais de interesse social térreas. 2013, 222f. Tese (Doutorado) - UFRGS, Porto Alegre.

Lozano, F. J., Lozano, R. (2014) Developing the curriculum for a new Bachelor's degree in Engineering for Sustainable Development. Journal of Cleaner Production, 64(1), 136-146.

Lowe, R., Oreszczyn, T. (2008) Regulatory standards and barriers to improved performance for housing. Energy Policy 36, 4475-4481.

Lucena, J., Schneider, J., Leydens, J. (2010) Engineering and sustainable development. Morgan and Claypool, San Rafael, CA.

Mattos, P. L. C. L. (2005) A entrevista não-estruturada como forma e conversação: razões e sugestões para sua análise. RAP, 39(4), 823-847. 
McLeod, R., Hopfe, C., Rezgui, Y. (2012) An investigation into recent proposals for a revised definition of zero carbon homes in the UK. Energy Policy 46, 25-35.

Molina J. C., Calil Junior, C. (2010) Sistema construtivo em Wood Frame para casas de madeira. Ciências Exatas e Tecnológicas, 31(2), 143-156.

Motta, S., Aguillar, M. (2009) Sustentabilidade e processos de projetos de edificações. Gestão \& Tecnologia de Projetos, 4(1), 84-119.

Nunes, V.Q.G. (2011) Análise estrutural de edifícios de paredes de concreto armado. 2011. 152f. Dissertação Mestrado em Engenharia de Estruturas) - Departamento de Engenharia Civil, Universidade Federal de São Carlos, São Carlos.

Oliveira, L. A., Mitidieri Filho, C. V. (2012) O projeto de edifícios habitacionais considerando a norma brasileira de desempenho: análise aplicada para as vedações verticais. Gestão e Tecnologia de Projetos, 7(1), 90-100.

PBMC - Painel Brasileiro de Mudanças Climáticas. (2012) Sumário executivo do volume 1 - Base científica das mudanças climáticas. Contribuição do Grupo de Trabalho 1 para o $1^{\circ}$ relatório de avaliação nacional do painel brasileiro de mudanças climáticas. Volume especial para a Rio+20, 2012. Recuperado em: 16 nov.2014, de: <http://www.insa.gov.br/wp-content/themes/insa_theme/acervo/painelbrasileiro>.

Reid, L.A., Houston, D. (2013) Low carbon housing: a 'green' wolf in sheep's clothing? Housing Stud. 28 (1), 1-9.

Reis, A T. L., Lay, M. C. D. (2006) Avaliação da qualidade de projetos - uma abordagem perceptiva e cognitiva. Ambiente Construído [online], 6(3), 21-34.

Rodríguez, G., Alegre, F. J., Martínez, G. (2011) Evaluation of environmental management resources (ISO 14001) at civil engineering construction worksites: A case study of the community of Madrid. $J$ Environ Manage. 92(7), 1858-66.

Santos, W. S., Dardengo, C. F. R., Carvalho, C. C., Alvarenga, R. C. S. S., Silva, R. C. (2014) Prescrições para construções de edificações residenciais multifamiliares com base nas patologias identificadas na cidade de Viçosa-MG. Revista de Engenharia e Tecnologia, 6(2), 104-123.

Sebrae SC.(2014) Critérios de classificação de empresas: EI - ME - EPP. Recuperado em: 21 nov.2014, de: <http://www.sebrae-sc.com.br/leis/default.asp?vcdtexto=4154>.

Shen, L. Y., Tam, W. Y., Tam, C. M., \& Drew, D. (2004) A mapping approach forexamining waste management on construction site. Journal of Construction Engineering \& Management, 130(4), 472-482.

Silva Junior, J. V. (2014) Edificações com certificação LEED: análise qualitativa do impacto financeiro gerado para obtenção da certificação em edificações de classe média. 2014, 78f. Trabalho de Conclusão e Curso (Engenharia Civil) - UFRGS, Porto Alegre.

Silva, A. T., Kern, A. P., Piccoli, R., González, M. A. S. (2014) Novas exigências decorrentes de programas de certificação ambiental de prédios e de normas de desempenho na construção. Arquitetura Revista, 10(2), 105-114.

Sinduscon - Sindicato da Indústria da Construção Civil (2014). Pesquisa FURB. [mensagem pessoal]. Recuperado em: 29 set.2014, de : < jessica.trettin@hotmail.com>.

Sorgato, M. J.; Melo, A. P.; Marinoski, D. L.; Lamberts, R. (2014) Análise do procedimento de simulação da NBR 15575 para avaliação do desempenho térmico de edificações residenciais. Ambient. constr.[online], 14(4), 83-101.

Sousa, L. R. T.; Ribeiro, J. F. (2013) Perfil socioambiental dos trabalhadores da construção civil do Setor de Habitações Coletivas Noroeste como base para ações em Educação Ambiental, Distrito Federal, Brasil. Rev. Eletrônica Mestr. Em Educ. Ambient, 30(2), 253-273.

Song, W. (2014). Decoupling cultivated land loss by construction occupation from economic growth in Beijing. Habitat International, 43, 198-205. 
Tam, W. Y. V.; Shen, L. Y.; Fung, W. H. I.;Wang, J. Y. (2007). Controlling construction waste by implementing governmental ordinances in Hong Kong. Construction Innovation: Information, Process, Management, 7(2), 149-166.

Tannuri, G., Van Bellen, H. M. (2014) Indicadores de desempeno ambiental evidenciados nos relatórios de sustentabilidade: uma análise à luz de atributos de qualidade. Revista de Gestão Social e Ambiental, 8(1), 219.

Tan, Y., Ochoa, J. J., Langston, C., \& Shen, L. (2015) An empirical study on the relationship between sustainability performance and business competitiveness of international construction contractors. Journal of Cleaner Production, 93, 273-278.

Tan, Y., Shen, L., \& Yao, H. (2011) Sustainable construction practice and contractors' competitiveness: A preliminary study. Habitat International, 35(2), 225-230.

Tessaro, A. B.; SA, J. S.; Scremin, L. B. (2012) Quantificação e classificação dos resíduos procedentes da construção civil e demolição no município de Pelotas, RS. Ambiente Construído [online], 12(2), 121-130.

Triana, M. A. Diretrizes para incorporar conceitos de sustentabilidade no planejamento e projeto de arquitetura residencial multifamiliar e comercial em Florianópolis. (2005). Dissertação (Mestra do em Arquitetura e Urbanismo) - Programa de Pós-graduação em Arquitetura e Urbanismo, Universidade Federal de Santa Catarina, Florianópolis.

Uber, P. A. (2015) Avaliação dos volumes dos reservatórios de captação de água de chuva para atendimento da Lei Complementar $n^{o} 691$ do município de Blumenau. Trabalho de Conclusão de Curso. (Graduação em Engenharia Civil) - Fundação Universidade Regional de Blumenau.

UNEP - Sustainable Buuildings \& Climate Initiative. (2009) Buildings and Climate Change - Summary for Decision-Makers. Recuperação em 23 dez.2015, de: <http://www.unep.org/sbci/pdfs/SBCIBCCSummary.pdf $>$.

Van Kleef, J.A.G., Roome, N.J. (2007) Developing capabilities and competence for sustainable business management as innovation: a research agenda. Journal of Cleaner Production, 15, 38-51.

Varnäs, A.; Balfors, B.; Faith-Ell, C. (2009). Environmental consideration in procurement of construction contracts: current practice, problems and opportunities in Green procurement in the Swedish construction industry. Journal of Cleaner Production, 17(3), 1214-1222.

Williams, C., Millington, A. (2004) The diverse \& contradictory meanings of sustainable development. Geogr. J. 170 (2), 99-104.

Yeheyis, M., Hewage, K., Alam, M. S., Eskicioglu, C., \& Sadiq, R. (2013). An overview of construction and demolition waste management in Canada: a lifecycle analysis approach to sustainability. Clean Technologies and Environmental Policy, 15(1), 81-91.

Zhang, Z. H., Shen, L. Y., \& Scott, D. (2000). Promoting urbanization towards sustainable development in China. Journal of Tsinghua University (Science and Technology), 40(1), 1-6.

Zuo, J., Read, B., Pullen, S., Shi, Q. (2012) Achieving carbón neutrlity in comercial building developments Perceptions of the construction industry. Habitat Internacional 36(2), 278-286.

Data da submissão: 23/09/2015

Data da publicação: 30/04/2016 